\title{
In situ reduction of (100) $\mathrm{SrTiO}_{3}$
}

Maria S. Martín González a, Myriam H. Aguirre a, Emilio Morán a, Miquel Á. AlarioFranco $^{\mathrm{a}, *}$, Virginia Perez-Dieste ${ }^{\mathrm{b}}$, José Ávila ${ }^{\mathrm{b}, \mathrm{c}}$, Maria C. Asensio ${ }^{\mathrm{b}, \mathrm{c}}$

a. Laboratorio de Química del Estado Sólido, Departamento de Química Inorgánica, Facultad de Ciencias Químicas, Universidad Complutense, 28040 Madrid, Spain

b. LURE, Bat 209D, Uni6ersite`Paris-Sud, F91405 Orsay, France

c. Instituto de Ciencia de Materiales de Madrid (CSIC), Cantoblanco 28049 Madrid, Spain

\begin{abstract}
Low energy electron diffraction (LEED) and photoelectron spectroscopy (PES) have been employed to study the (100) $\mathrm{SrTiO}_{3}$ surface annealed in ultra high vacuum. The annealing was performed up to $830^{\circ} \mathrm{C}$. After annealing at $830^{\circ} \mathrm{C}$, we have observed from PES spectra the appearance of the conduction band and from LEED patterns the $(\sqrt{5} \times \sqrt{5}) \mathrm{R} 26.6^{\circ}$ superstructure. Both features seem to have the same origin: the ordering of oxygen vacancies.
\end{abstract}

Keywords: Strontium titanate; Reduction; PES; LEED; Ordered oxygen vacancies

\section{Introduction}

Strontium titanate, a perovskite with band-gap energy of $3.2 \mathrm{eV}$ at $25^{\circ} \mathrm{C}$ [1], is a 'classic' in Solid State Science because of its interesting properties. Basically an insulator, it becomes semi- and even superconducting upon reduction [2], i.e. oxygen extraction. Yet, this is not the only reason why the surface of $\mathrm{SrTiO}_{3}$ is lately the focus of interest. Also, and depending on the stoichiometry, it becomes ferroelectric, in contrast to the pristine $\mathrm{SrTiO}_{3}$. It is one of the few stable materials that can decompose water into hydrogen and oxygen with the assistance of light (photoelectrolysis) [3], although with a relatively low yield. Moreover, $\mathrm{SrTiO} 3$ has been found as one of the most suitable substrates for the epitaxial growth of high $T c$ superconducting $\mathrm{YBa}_{2} \mathrm{Cu}_{3} \mathrm{O}_{7-\mathrm{x}}$ films. Nevertheless, its reduction process is still unclear $[4,5]$. In the present work we have tried to understand such a process.

\section{Experimental}

The photoelectron spectroscopy (PES) experiments were performed in an ultrahigh vacuum (UHV: $P<10^{-10}$ mbar) chamber equipped with an angle-resolved hemispherical analyzer mounted in a goniometer and with a high-precision manipulator. The experiments were carried out using synchrotron light from the Spanish-French beam line (SU8) of the Super-Aco storage ring in Orsay. The measurements were performed using linear polarised light with an overall energy resolution better than $100 \mathrm{meV}$. The low energy electron diffraction (LEED) patterns were recorded at different energies by a video camera connected to a computer. In the present experiment, single crystalline samples $(5 \times 5 \times 1 \mathrm{~mm})$ of $\mathrm{SrTiO}_{3}(100)(\mathrm{Crystal}-\mathrm{GmbH})$ were fixed on a silicon resistive heater. They were annealed 
at different temperatures in subsequent thermal treatments $\left(300,640,750,830^{\circ} \mathrm{C}\right)$ under UHV conditions for different periods of time (see Table 1).

Table 1. $\mathrm{SrTiO}_{3}(100)$ heat treatment in $10^{-7}$ mbar

\begin{tabular}{lcc}
\hline Sample & Temperature $\left({ }^{\circ} \mathrm{C}\right)$ & Time $(\mathrm{min})$ \\
\hline A & - & - \\
B & 300 & 30 \\
C & 640 & 60 \\
D & 750 & 20 \\
E & 750 & 70 \\
F & 830 & 120 \\
\hline
\end{tabular}

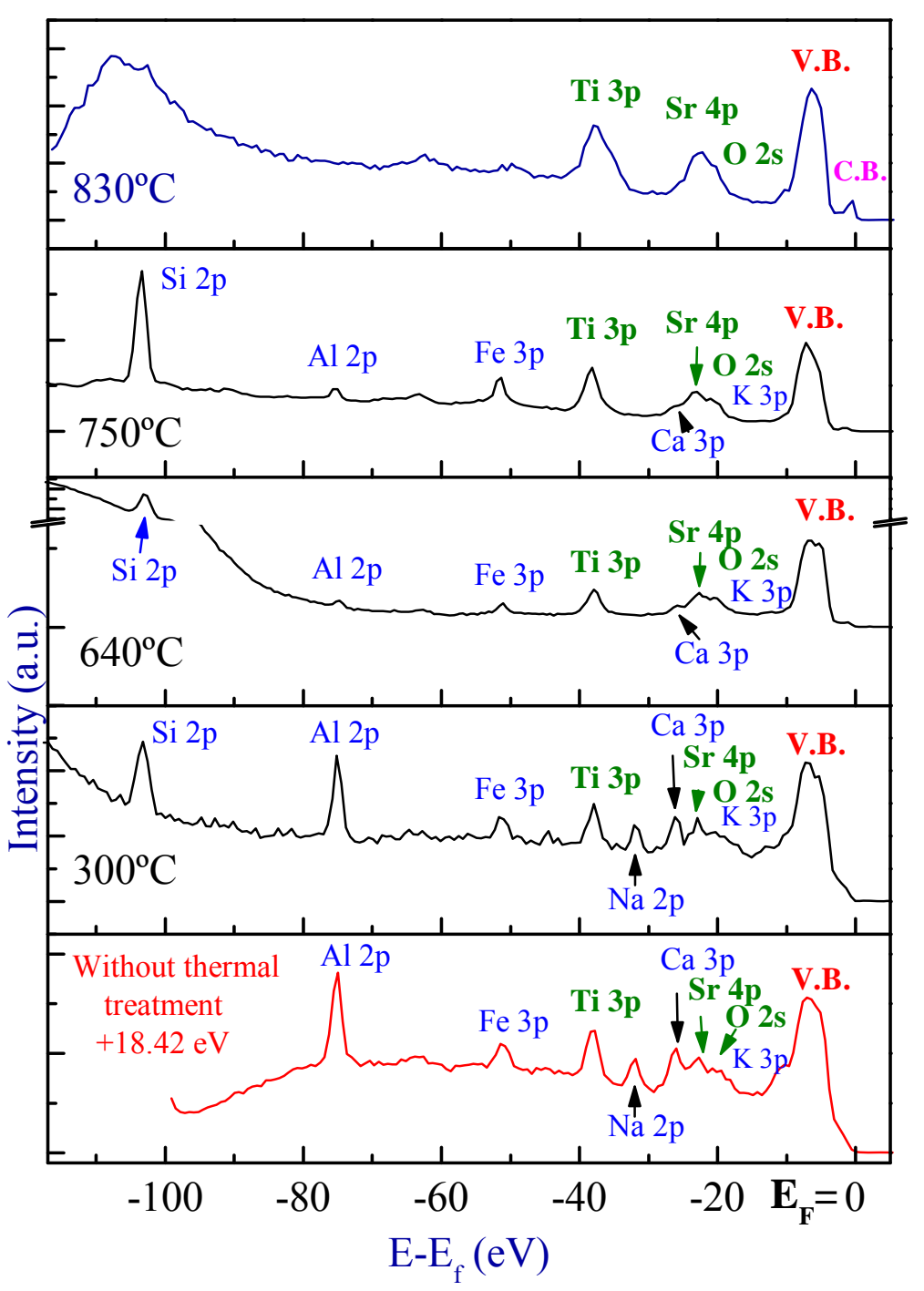

Fig. 1. Photoemission overview of $\mathrm{SrTiO}_{3}$ (100) surface, treated at different temperatures in UHV. Photon energy $130 \mathrm{eV}$. 
Temperatures were measured with an optic pyrometer. In all the cases, the pressure in the preparation chamber during the thermal treatment was of the order of $10^{-7} \mathrm{mbar}$. Then, they were cooled down at room temperature and, afterwards, LEED and PES were used to examine the structure and composition of the surface at pressure $\approx 10^{-10}$ mbar. The PES spectra were measured at $130 \mathrm{eV}$ for every temperature and the LEED patterns were taken at 167, 133, 106, 98 and $42 \mathrm{eV}$. The position of the Fermi level $\left(E_{\mathrm{F}}\right)$ has been determined by comparison with the measured Fermi edge of a copper film mounted besides the sample.

\section{Results and discussion}

\subsection{Photoelectron spectroscopy}

As is well known, the heating of $\mathrm{SrTiO}_{3}$ at temperature $\geq 500^{\circ} \mathrm{C}$ in ultra high vacuum generates $n$-type conductivity due to the reduction process $\left(\mathrm{Ti}^{4+} \rightarrow \mathrm{Ti}^{3+}\right)$ that accompany the oxygen vacancies produced [6,7]. Also, according to previous studies, when the sample is heated to temperatures higher than $600^{\circ} \mathrm{C}$ in ultra high vacuum, $\left(10^{-10}\right)$ carbon and water contamination disappear from the surface $[8,9]$. This allows us to study the samples by two different surface probes: PES and LEED, since the sample presents enough conductivity to be studied by these techniques.

Fig. 1 shows an overview of the sample surface at different temperatures as seen by PES spectra. The spectra obtained without any previous thermal treatment has an $18.42 \mathrm{eV}$ shift with respect to the others. This is due to the insulating characteristic of the pristine $\mathrm{SrTiO}_{3}$. The shift disappears when the sample is being annealed up to $300^{\circ} \mathrm{C}$. This is indicative of the sample becoming conducting.

In this same spectrum of Fig. 1, without treatment, apart from the valence band (VB), and the $\mathrm{Ti}, \mathrm{Sr}$ and $\mathrm{O}$ core level peaks, the presence of other bands can also be observed; these can be indexed as due to some impurities (see Table 2; quality suggested by the supplier: Crystal-GmbH). Therefore, impurities like $\mathrm{Si}, \mathrm{Al}, \mathrm{Fe}, \mathrm{Ca}, \mathrm{Na}$, and $\mathrm{K}$ are present on the surface, while Ba must be in the bulk. As the temperature of the thermal treatment increase the crystal darkens and, as can be observed in Fig. 1, some of these impurities peaks start to disappear.

After an $830^{\circ} \mathrm{C}$ annealing, some of the impurity bands ( $\mathrm{Al}, \mathrm{Fe}$ and $\mathrm{Na}$ ) completely disappear, while others like $\mathrm{Ca}$ nearly do so. This means that the surface is becoming free of them. Nevertheless, the same cannot be said for the Si band, because it overlaps with the background of the inelastic electrons produced during the photoemission.

Furthermore, these are not the unique important changes in the spectrum: the $\mathrm{Ti}, \mathrm{Sr}$ and $\mathrm{O}$ core levels also change and a new band, meaning the Fermi level, starts to appear at $830^{\circ} \mathrm{C}$ : the conduction band. All these peaks are directly related to the reduction process. For this reason it is worth studying them in some detail.

The PES spectrum of the Ti (3p) level (Fig. 2) shows that when SrTiO3 is heated at high temperature $\left(>640^{\circ} \mathrm{C}\right)$ a new band starts to appear. This new component (observed on the right side of the peak) appears during annealing. In this way, the $\mathrm{Ti}(3 \mathrm{p})$ core level spectrum shows at smaller energies the consequences of the elimination of oxygen. To preserve the electrical neutrality of the lattice some $\mathrm{Ti}^{4+}$ is transformed in $\mathrm{Ti}^{3+}$. Moreover, at $830^{\circ} \mathrm{C}$ an 
increasing of the $\mathrm{Ti}^{3+}$ peak relative to $\mathrm{Ti}^{4+}$ is observed and another new component appears. Due to its position, it can be attributed to the presence of $\mathrm{Ti}^{2+}$. Consequently, titanium seems to be in three different oxidation states, Ti(II), Ti(III), Ti(IV).

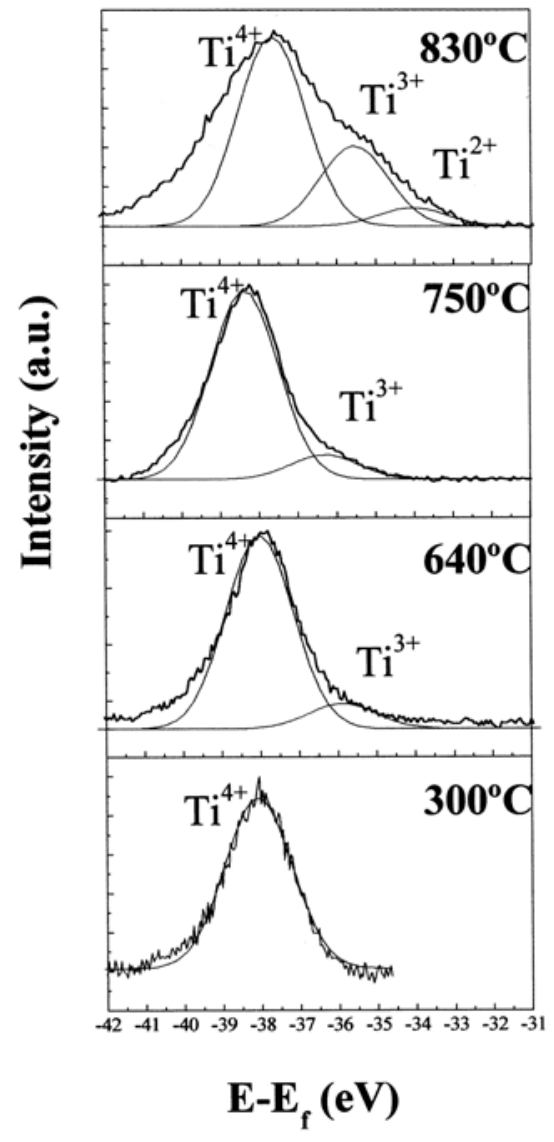

Fig. 2. PES spectra of $\mathrm{SrTiO}_{3}$ (100) surface, treated at different temperatures in UHV. Core level of $\mathrm{Ti}(3 \mathrm{p})$. Photon energy $130 \mathrm{eV}$.

Another region of the PES spectrum, which shows an important change, is close to the $\mathrm{Sr}$ core level (Fig. 3). This emission seems to be quite complicated since it includes the contributions of $\mathrm{Ca}, \mathrm{Sr}, \mathrm{O}$ and $\mathrm{K}$. At $830^{\circ} \mathrm{C}$ the peak corresponding to the $\mathrm{Ca}(3 \mathrm{p})$ and $\mathrm{K}$ (3p) core levels have mostly disappeared (Fig. 3). This means that the surface is becoming free of them. Moreover, at $830^{\circ} \mathrm{C}$ a decreasing of the $\mathrm{O}$ peak relative to the $\mathrm{Sr}$ one is observed (from $1 / 2$ in the spectrum for the sample without treatment to $2 / 5$ at $830^{\circ} \mathrm{C}$ ). This indeed means that, when heating oxygen is going out of the sample. The oxygen band position is in good agreement with that suggested by See et al. for stoichiometric $\mathrm{SrTiO}_{3}$ [10]. 


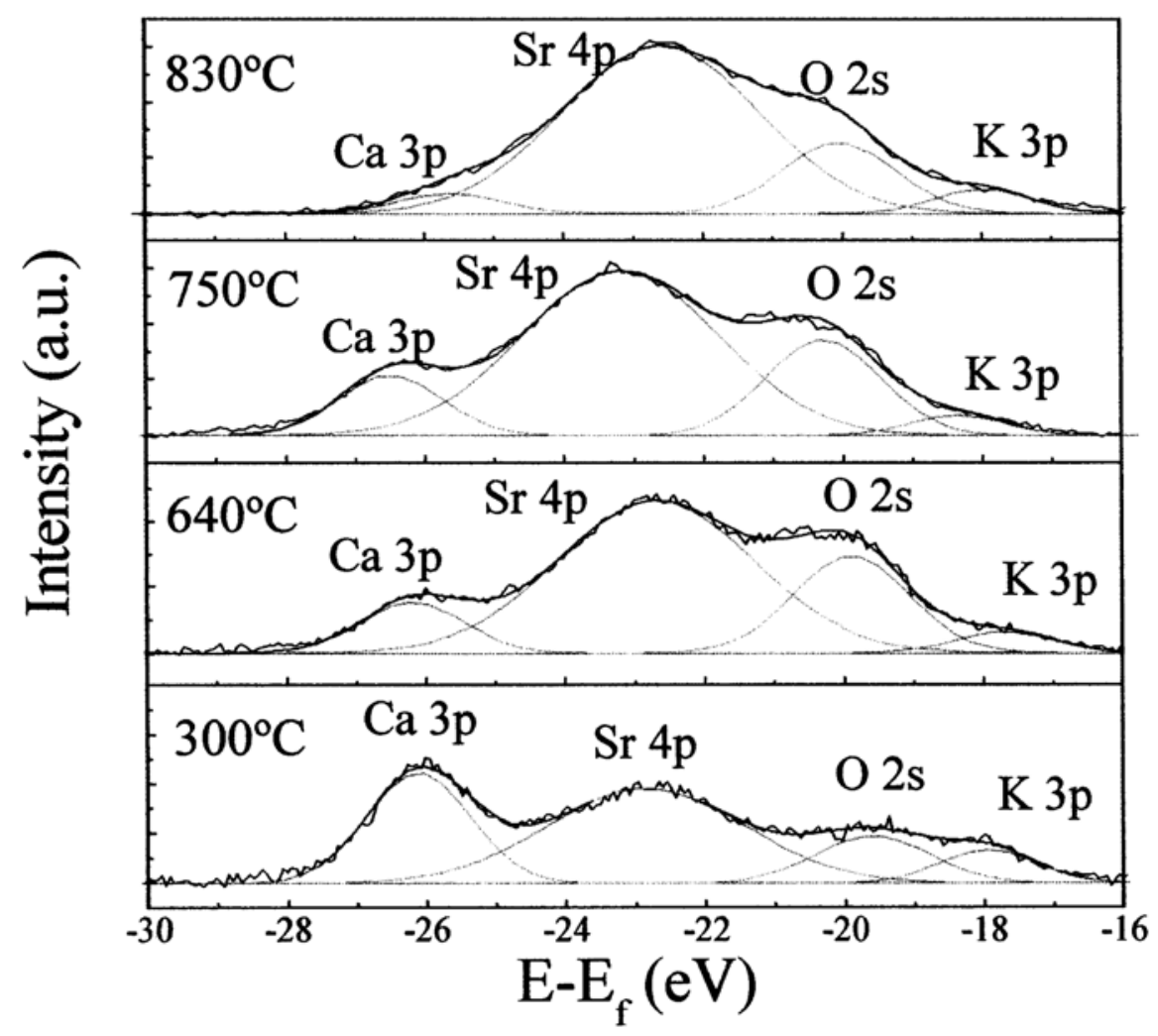

Fig. 3. PES spectra of SrTiO3 (100) surface, treated at different temperatures in UHV. Core levels of $\mathrm{Ca}(3 \mathrm{p}), \mathrm{Sr}(4 \mathrm{p}), \mathrm{O}(2 \mathrm{~s})$ and $\mathrm{K}(3 \mathrm{p})$. Photon energy $130 \mathrm{eV}$.

Table 2. Chemical analysis of the $\mathrm{SrTiO}_{3}$ single crystals and its binding energies

\begin{tabular}{|c|c|c|c|}
\hline Element & Concentration (ppm) & \multicolumn{2}{|c|}{ Binding energy $(\mathrm{eV})$} \\
\hline \multirow[t]{2}{*}{ Al } & 10 & $2 \mathrm{p}_{1 / 2}$ & 72.9 \\
\hline & & $2 \mathrm{p}_{3 / 2}$ & 72.5 \\
\hline \multirow[t]{2}{*}{$\mathrm{Ba}$} & 19 & $4 d_{3 / 2}$ & 92.6 \\
\hline & & $4 d_{5 / 2}$ & 89.9 \\
\hline \multirow[t]{2}{*}{$\mathrm{Ca}$} & 14 & $3 p_{1 / 2}$ & 25.4 \\
\hline & & $3 p_{3 / 2}$ & 25.4 \\
\hline \multirow[t]{2}{*}{$\mathrm{Fe}$} & $<2$ & $3 \mathrm{p}_{1 / 2}$ & 52.7 \\
\hline & & $3 p_{3 / 2}$ & 52.7 \\
\hline \multirow[t]{2}{*}{ K } & 2 & $3 \mathrm{p}_{1 / 2}$ & 18.3 \\
\hline & & $3 p_{3 / 2}$ & 18.3 \\
\hline \multirow[t]{2}{*}{$\mathrm{Na}$} & $<2$ & $2 \mathrm{p}_{1 / 2}$ & 30.4 \\
\hline & & $2 \mathrm{p}_{3 / 2}$ & 30.4 \\
\hline \multirow[t]{2}{*}{ Si } & $<2$ & $2 \mathrm{p}_{1 / 2}$ & 99.8 \\
\hline & & $2 \mathrm{p}_{3 / 2}$ & 99.2 \\
\hline
\end{tabular}

The reduction of $\mathrm{SrTiO}_{3}$ also originates the appearance of a new band between the Fermi level $\left(\mathrm{E}_{\mathrm{f}}\right)$ and the VB: the conducting band (see Fig. 4). This new band is generated by the reduction of $\mathrm{Ti}^{4+}=(\mathrm{Ar}) 3 \mathrm{~d}^{0}$ to $\mathrm{Ti}^{3+}(\mathrm{Ar}) 3 \mathrm{~d}^{1}$, so that the promotion of electrons, from the $\mathrm{VB}$ to the conduction, does occur. The gap observed at $830^{\circ} \mathrm{C}$ is $3.2 \mathrm{eV}$. 


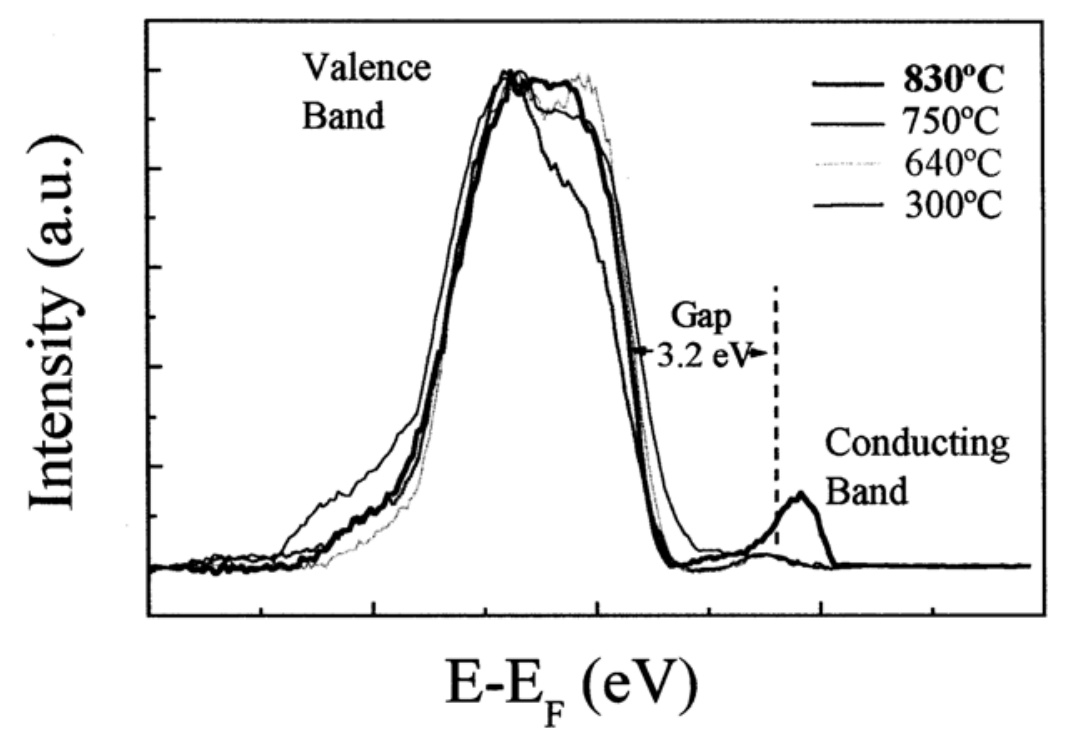

Fig. 4. VB for different temperatures. Photon energy $130 \mathrm{eV}$.

\subsection{LEED results}

Fig. 5 shows the LEED diagrams for each temperature at $98 \mathrm{eV}$. Until $640^{\circ} \mathrm{C}$ LEED was not detected. At $640^{\circ} \mathrm{C}$ the patterns exhibit sharp spots over a low background, indicating a smooth and well ordered surface: a typical $\mathrm{P}(1 \mathrm{x} 1)$, characteristic of a (100) orientation of a cubic perovskite. The oxygen vacancy concentration is neither high enough to produce conductivity nor to produce a surface reconstruction. It is worth mentioning that shell model calculation [15] and STM [11-14] works have shown that the (100) $\mathrm{SrTiO}_{3}$ surface is Ti-Oterminated. The same pattern was detected up to $740^{\circ} \mathrm{C}$ (see Fig. 5). Nevertheless, after the annealing at $830^{\circ} \mathrm{C}$ during $2 \mathrm{~h}$, a new superstructure is found. In Fig. 6, patterns taken at different voltages are shown and they can be described in k-space, as fractional spots, based on the primitive crystal structure perovskite in two dimensions $\approx 3.9 \times 3.9 \AA$, . They appear at $(2 / 5,1 / 5),(4 / 5,2 / 5),(1 / 5,3 / 5)$ and $(3 / 5,4 / 5)$ for the first group, and $(1 / 5,2 / 5),(3 / 5,1 / 5)$, $(2 / 5,4 / 5)$ and $(4 / 5,3 / 5)$ for the second group with respect to the $\mathrm{P}(1 \mathrm{x} 1)$ pattern; the two sets can be transformed into each other by rotating $36.87^{\circ}$ and correspond to two domain sets (Fig. 7). The vectors of the primary unit cell in k-space are $[2 / 5,1 / 5] ;[1 / 5,3 / 5]$ for the first domain set and $[3 / 5,1 / 5] ;[1 / 5,2 / 5]$ for the second one. Transforming into real space and taking into account that the most favorable top layer is the titanium-oxygen one, we find that the LEED pattern corresponds to a $(\sqrt{5} \times \sqrt{5}) \mathrm{R} 26.6^{\circ}$ reconstruction. The ordering of the oxygen vacancies in two intergrown domain sets, at the top layer of $\mathrm{SrTiO}_{3}$, it seems to be responsible for it rather than the presence of impurity aggregation in the crystal surface as other authors have proposed [16]. The corresponding model is illustrated in Fig. 8. Up to now, this reconstruction in $\mathrm{SrTiO}_{3-\mathrm{x}}$ had only been detected by techniques like STM and RHEED [17-19] when $\mathrm{SrTiO}_{3}$ is heated at $1200^{\circ} \mathrm{C}$ in vacuum for several minutes. Other types of reconstruction have been observed in this material [15], for example $\operatorname{SrTiO}_{3-x}(3 \mathrm{x} 2)$ by Tomashpol'skii et al. [20]. 

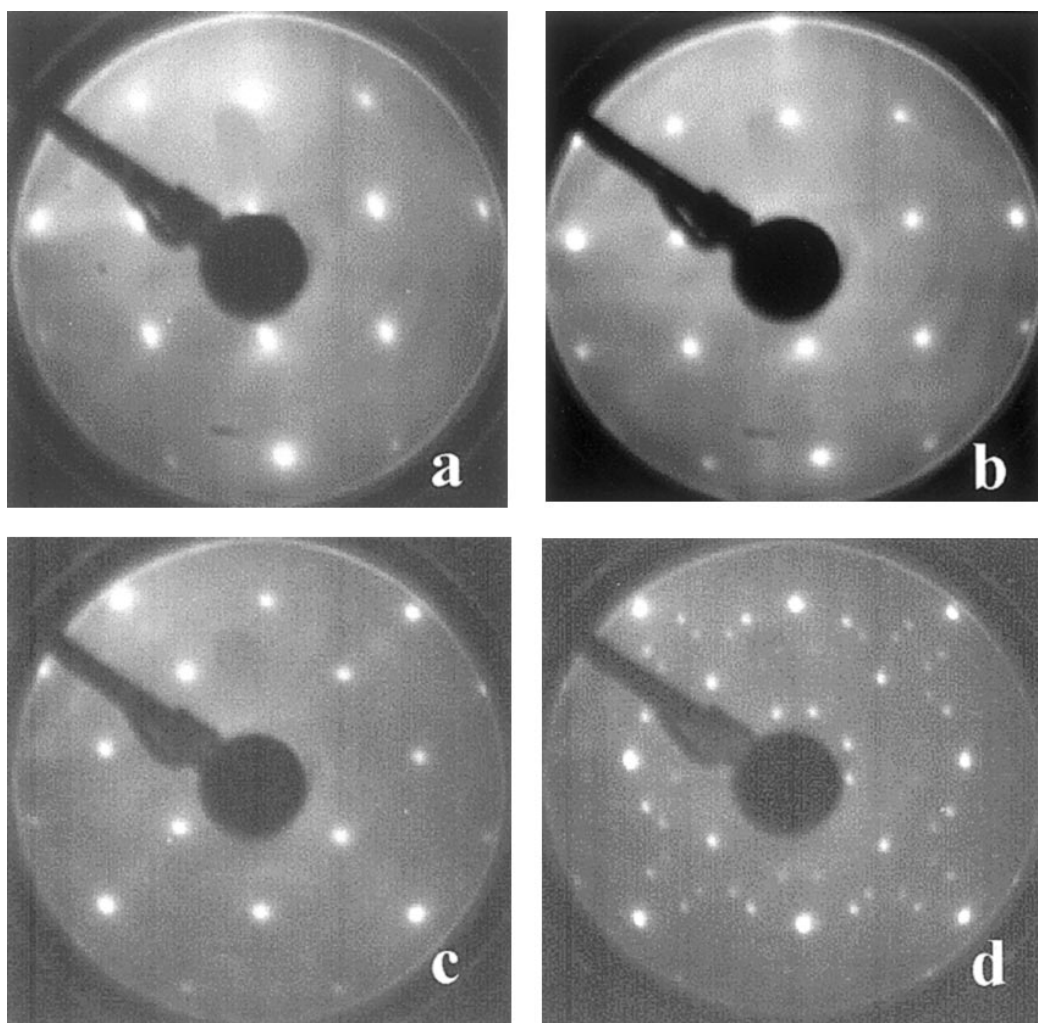

Fig. 5. LEED patterns from SrTiO3 (100), Ep_98 eV at different temperatures. (a) $640^{\circ} \mathrm{C}$ for $60 \mathrm{~min}$, (b) $750^{\circ} \mathrm{C}$ for $20 \mathrm{~min}$, (c) $70 \mathrm{~min}$, and (d) $830^{\circ} \mathrm{C}$ for $120 \mathrm{~min}$, in accumulative thermal treatment.
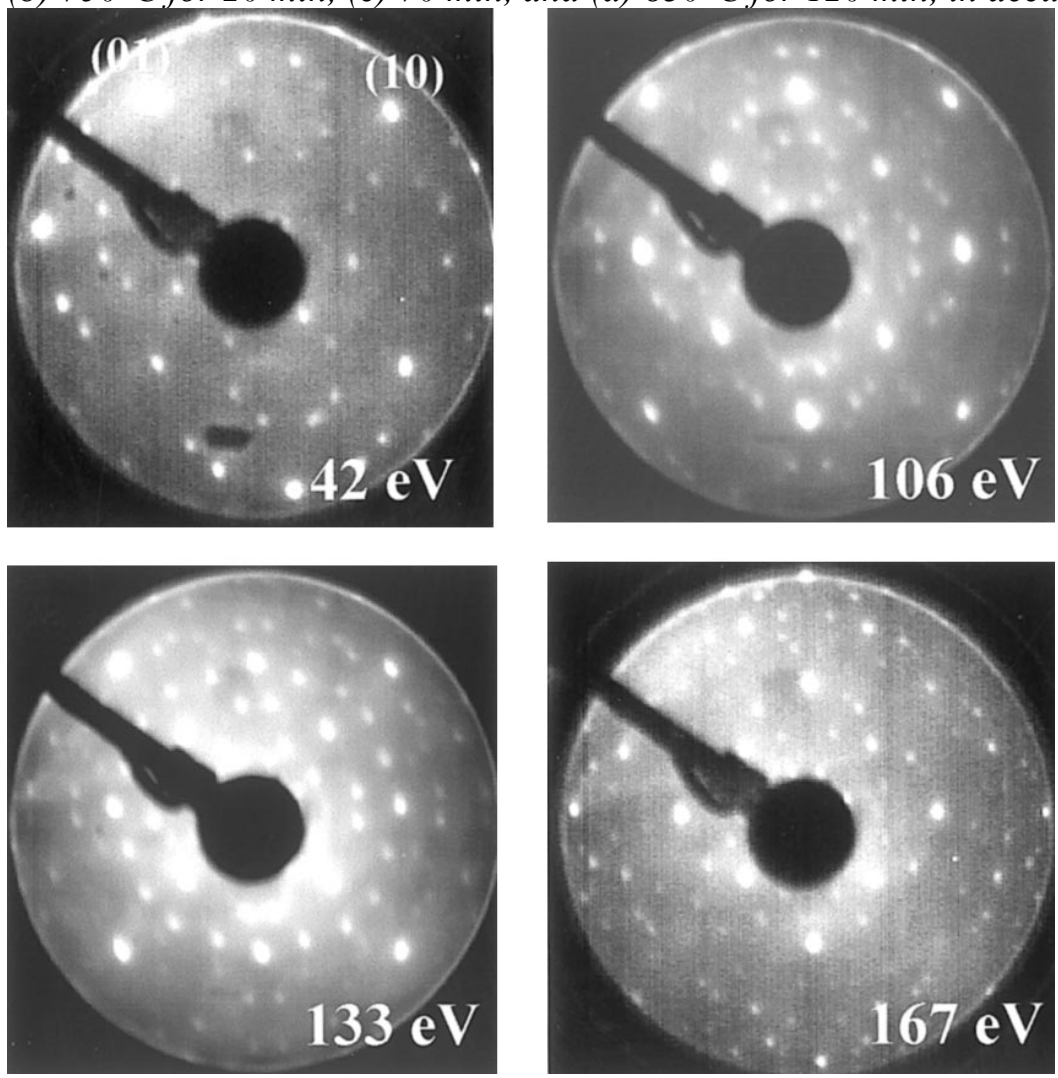

Fig. 6. LEED patterns from SrTiO3 (100), at different photon energy (167, 133, 106 and $42 \mathrm{eV})$ after $830^{\circ} \mathrm{C}$ annealing in vacuum. 


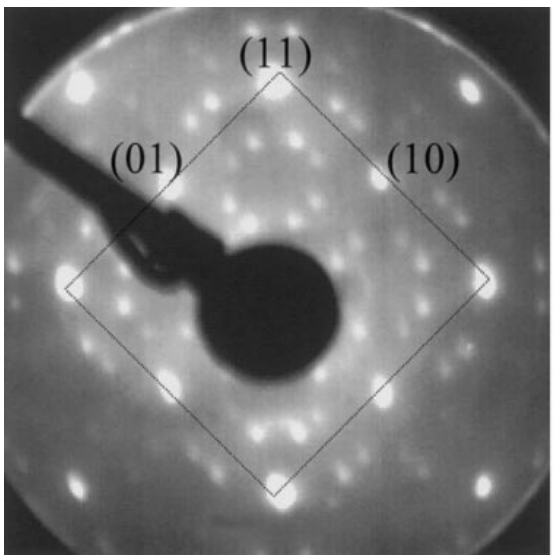

$(01)$

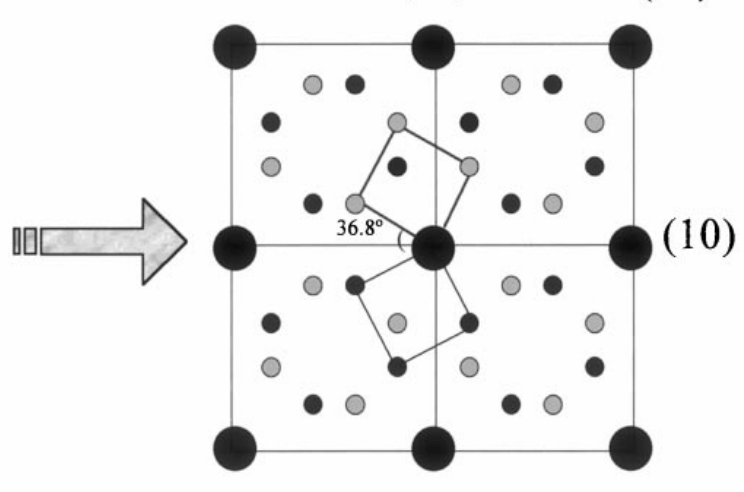

Fig. 7. Reciprocal unit cell. It is the result of two $(\sqrt{ } 5 x \sqrt{5}) R 26.6^{\circ}$, intergrown domain sets rotated $36.87^{\circ}$ from each other.
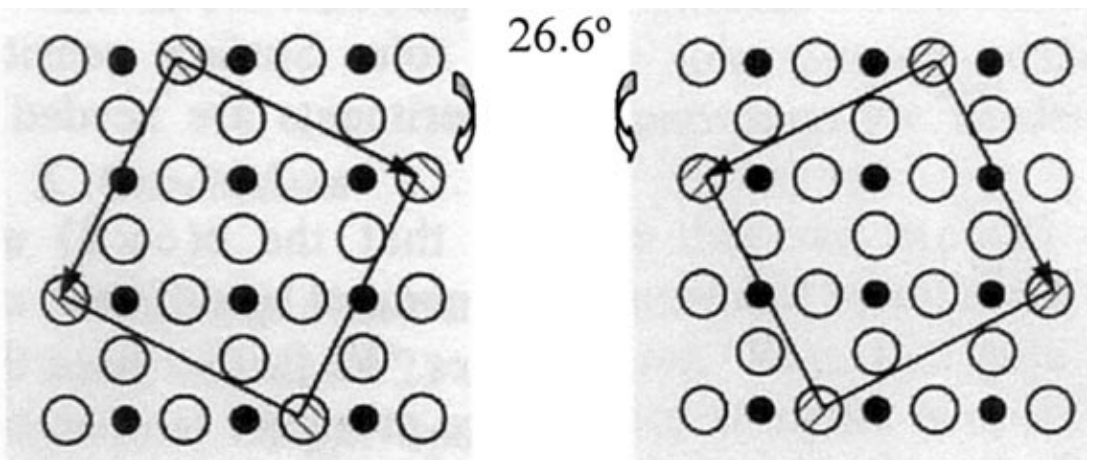

\section{$\sqrt{5} \times \sqrt{5} \mathrm{R} 26.6$}

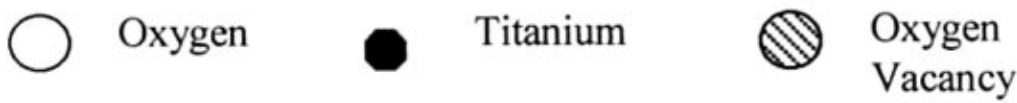

Fig. 8. A model in the real space of $\mathrm{SrTiO}_{3}(\sqrt{5} \times \sqrt{5}) \mathrm{R} 26.6^{\circ}$, the oxygen vacancies are ordered along the $<120>$ direction in the $\mathrm{TiO}_{2}$ top layer.

\section{Conclusions}

The annealing in UHV produces enough conductivity (n-type) to allow electron spectroscopy and diffraction using synchrotron radiation to be performed in $\mathrm{SrTiO}_{3-\mathrm{x}}$. Impurities like $\mathrm{Al}, \mathrm{Fe}, \mathrm{Na}, \mathrm{Ca}$ disappear from the surface when the sample is heated at $830^{\circ} \mathrm{C}$ in UHV. The elimination of oxygen from $\mathrm{SrTiO}_{3}$ originates a new band between the Fermi level and the VB: the conduction band. This new band is related to the presence of $\mathrm{Ti}^{3+}$ in the surface. After $830^{\circ} \mathrm{C}$ annealing in vacuum for $2 \mathrm{~h}$, a superstructure is observed by LEED. It can be scribed as two $(\sqrt{5} \times \sqrt{5}) R 26.6^{\circ}$ intergrown domain sets rotated $36.87^{\circ}$ from each other. 


\section{References:}

[1] M. Cardona, Phys. Rev. A 651 (1965) 140.

[2] J.F. Schooley, W.R. Hosler, M.L. Cohen, Phys.Rev. Lett. 12 (1964) 474.

[3] J.G. Mavroides, J.A. Kafalas, D.F. Kolisar, Appl. Phys.Lett. 28 (1976) 241.

[4] M.A. Alario-Franco, M. Vallet-Regi, Nature 270 (1977) 706.

[5] W. Gong, H. Yun, Y.B. Ning, J.E. Greedan, W.R. Datars, C.V. Stager, J. Solid State Chem. 90 (1991) 320.

[6] V.E. Henrich, G. Dresselhaus, H.J. Zeiger, Phys. Rev. B 17 (1978) 4908.

[7] R. Courths, B. Cord, H. Saalfeld, Solid State Comm. 70 (1989) 1047.

[8] M. Kawasaki, A. Ohtomo, T. Arakane, K. Takahashi, M.Yoshimoto, H. Koinima, Appl. Surf. Sci. 107 (1996) 102.

[9] J.E.T. Andersen, P.J. Moeller, Appl. Phys. Lett. 56 (1847) 1990.

[10] A.K. See, W.K. Siw, R.A. Bartynski, A. Nangia, A.H. Weiss, S.L. Hulbert, X. Wu, C.C. Kao, Surf. Sci. 383 (1997) L735.

[11] M. Yoshimoto, T. Maeda, K. Shimozono, H. Koinuma, M.Shinohara, O. Ishiyama, F. Ohtani, Appl. Phys. Lett. 65 (1994) 3197.

[12] V.E. Henrich, P.A. Cox, The Surface Science of Metal Oxides, Cambridge University Press, Cambridge, UK, 1996.

[13] T. Chien, J.S. Speck, F.F. Lange, A.C. Daykin, C.G. Levi, J.Mater. Res. 10 (1995) 1784.

[14] M. Kawasaki, K. Takahasi, T. Maeda, R. Tsuchiya, M.Shinohara, O. Ishiyama, T. Yonezawa, M. Yoshimoto, H.Koinuma, Science 266 (1994) 1540.

[15] Q.D. Jian, J. Zegenhagen, Surf. Sci. 425 (1999) 343.

[16] J.E.T. Andersen, P.J. Møller, Appl. Phys. Lett. 56 (1990) 1847.

[17] H. Tanaka, T. Matsumoto, T. Kawai, S. Kawai, Surf. Sci.318 (1994) 29.

[18] T. Matsumoto, H. Tanaka, K. Koukuchi, T. Kawai, S.Kawai, Surf. Sci. 312 (1994) 21.

[19] H. Tanaka, T. Matsumoto, T. Kawai, S. Kawai, Surf. Sci.278 (1992) L153.

[20] Y.Y. Tomashpol'skii, E.N. Lubnin, M.A. Sevostýanov, V.I.Kukuev, Kristallografiya 27 (1982) 1152. 